\title{
Growing Young Mathematicians: Engaging Young Learners with Mathematics through Designing and Planting a Garden
}

\author{
Leanna Lucero \\ New Mexico State University, Las Cruces, New Mexico, USA
}

Children use mathematics to make sense of their world long before they enter formal school settings by sorting and comparing objects, counting, and using mathematical reasoning. When children enter formal school settings, they are often exposed to decontextualized approaches of learning mathematics. In this article, I argue that moving beyond the walls of the classroom into a classroom garden engages young children with mathematics and increases children's early mathematical reasoning and mathematical identity development. Findings suggest working in a classroom garden during an after-school program over the course of one semester provided young children with multiple, and diverse, opportunities to engage with mathematical experiences, mathematical reasoning, and mathematical identity development. Through regular participation in a variety of gardening activities focused on designing and planting, young children engaged in mathematic-rich dialogue utilizing complex and abstract mathematic process skills such as making sense of problems and persevering in solving them, constructing viable arguments, critiquing the reasoning of others, strategically using appropriate tools, as well as looking for structure regularity in repeated reasoning.

Keywords: Early childhood, mathematics, gardens, community of practice, $21^{\text {st }}$ Century Learning Community Centers

Young children are naturally curious about the world in which they live (Clements, 2001). Long before children enter formal school settings, they use mathematics to make sense of their community. Children's understanding of mathematics prior to formal school settings is often nurtured and leveraged upon by doing mathematics - sorting objects, comparing objects, using nonacademic language to describe mathematical patterns and concepts, and so on and so forth. When young children enter formal school settings in the U.S., teachers often have difficulty in making concrete connections between children's previous knowledge and understanding of mathematics. That is, 
there is a challenge in making formal mathematics relevant to young children's everyday life and their experiences. These decontextualized approaches may result in young learners becoming disinterested in mathematics over time (Perlmutter et al., 1997).

As a current early childhood and elementary mathematics teacher educator/researcher and a former elementary math teacher, middle school math teacher, math coach, and administrator, I have experienced the struggles of balancing high stakes requirements and accountability with creating mathematical tasks that are relevant to children and honor their sociocultural, physical, developmental, cultural, and linguistic needs. In this article, I argue that moving beyond the walls of the classroom into a classroom garden engages young children with mathematics and increases children's early mathematical reasoning and mathematical identity development.

\section{Purpose and Methods}

The purpose of this study was to better understand the mathematical experiences of young children as they participated in a gardening class during an after-school program. Participants included a small group $(\mathrm{N}=22)$ of children in Kindergarten $(n=6), 1^{\text {st }}$ grade $(n=7)$, and $2^{\text {nd }}$ grade $(n=9)$. All 22 of the children were Hispanic, ten of the children identified as male, and twelve identified as female. Consent to participate was obtained from children and their parent(s) as well as permission to use photos.

The after-school program was funded by cycle 7 Texas $21^{\text {st }}$ Century Community Learning Centers (CCLC program) granted through the U.S. Department of Education initiative and administered by the Texas Education Agency (TEA) to deliver the Afterschool Center on Education (ACE) program. The grants are intended to provide opportunities for Texas communities to create learning centers that focus on academics and enrichment during afterschool time and target children and families in historically low performing schools and in low socio-economic communities (U.S. Department of Education, 2004). Learning centers are focused on improving student academic performance, school attendance, student behavior, promotion and graduation rates, and family engagement through afterschool and summer programs. The program was located at Valley Elementary School (pseudonym), a Title I campus with a student body of approximately 400 students in grades K-6. The student population is over $99 \%$ Hispanic and reflective of the community in which it is situated within 2 miles of the U.S./Mexico border. At the time of the study, I was the CCLC Site Coordinator at Valley Elementary School.

This article is informed by a gardening class I taught during an afterschool program that focused on supporting and reinforcing young children's understanding of mathematics concepts in grades K-2. In this class, I planned lessons, facilitated activities, and conducted informal observations of children 
interacting with one another-watching, listening, and taking photos as young children engaged in mathematical explorations in our outdoor garden. Although these methods did not approach the rigor of an empirical study, I was able to explore understandings related to my primary research question: What math experiences are afforded to children in grades K-2 while participating in gardening activities during an afterschool program?

\section{Community of Practice and Sociocultural Contexts}

In the following section, I conceptualize gardening as a community of practice with opportunities for research on mathematical learning within social contexts such as gardening. The theoretical framework for this study is guided by community of practice theory rooted in sociocultural perspectives and social contexts. Community of practice theory suggests learners develop their understanding and identity through collaboration and active participation within a social community, such as a classroom community (Lave \& Wenger, 1998; Wenger \& Lave, 2001). Over time members of a community develop an understanding of the practice, their knowledge of the practice within the community, and their identity within the specific community. Wenger (1998) explains engagement, imagination, and alignment as three types of belonging associated with community of practice. Using community of practice theory facilitates members' development of an identity within their social context and extends learning in formal and informal spaces.

By following a community of practice model, learners engage in meaning making through imagination and various interactions as they develop their understanding and align their knowledge with the community. Furthermore, learners make meaning of tools, concepts, and processes within the community and can begin to construct their own learning and understanding as well as increase their confidence as a member within the community of practice.

Integrating mathematics with real-world scenarios such as gardening responds to young children's sociocultural contexts because it provides them with opportunities to interact with mathematics and with one another in ways similar to their daily communication. Mathematics learning outside of the classroom involves more than modifications and accommodations for learners; it requires creating learning environments outside of the classroom and transforming traditional classrooms from spaces of passive learning to constructive spaces where learners demonstrate their knowledge in multiple ways and create pathways for identity construction amongst a community of emerging practitioners.

Young children gain agency and shape identities as learners when given autonomy to make connections, solve problems, and approach tasks through their own engagement rather than through following prescriptive curriculum materials such as worksheets and rote-based quizzes (AbodeebGentile \& Zawilinski, 2013). When real-world scenarios and contexts, such as 
gardens, become central to learner's interactions with mathematics, young children begin to associate mathematics with social contexts. Furthermore, students develop identities within their social context and extend learning both inside and outside formal classrooms and engage in meaning making through interactions and connections to real-world experiences (Blankenship \& Margarella, 2014). The role of the instructor as a facilitator of inquiry-driven, socialized, and constructivist learning is pivotal in empowering the transition of young learners from novice to an emerging expert practitioner (Lipman, 2010), in this case $\mathrm{K}-2^{\text {nd }}$ grade members of a gardening class funded by the Texas $21^{\text {st }}$ Century Community Learning Centers (CCLC; Cycle 7) program.

\section{Establishing the FEAR Factor $21^{\text {st }}$ Century Community Learning Center}

Since I was the CCLC Site Coordinator at Valley Elementary School when it was established, I was able to conceptualize a program that met the distinct needs and interests of the school community and adhered to grant requirements and expectations. During the first weeks of program recruitment and inception, I used a survey and informal conversations with students to better understand their interests in enrichment activities. I also used a survey and informal conversations with families to understand what types of supports they needed. Finally, I disaggregated data from state- and district-mandated assessment results to understand the academic needs of the students.

Survey results and informal conversations with students revealed that students were interested in sports (football, basketball, soccer, and cheerleading), robotics, cooking, art, and gardening. Families requested support in assisting their children with homework, adult ESL (English as a second language) classes, assistance with creating resumes, and family nights/activities that were engaging for the whole family. Results from assessment data showed that students historically underperformed on assessments in mathematics, science, and reading.

I used this information to create the $21^{\text {st }}$ Century STEAM FEAR Factor (Families, Enrichment, Academics, and college and career Readiness) Afterschool and Summer Program at Valley Elementary. The afterschool program was held Monday through Friday for 3 hours each day during the fall and spring semester, and the summer program was Monday through Thursday for approximately seven hours per day for five weeks. The $21^{\text {st }}$ Century FEAR Factor Program predominately focused on supporting students' academic performance in mathematics and science through their interests in robotics, cooking, art, and gardening. An average of 180 students participated in the program while I was the Site Coordinator, and close to $90 \%$ of those students (160 students) were considered regular students by the grant definition (students who attended at least 30 days of program during fall/spring).

As a former elementary teacher and middle school math teacher, I was excited to instill a passion for mathematics in young learners as well as 
facilitate the learning of mathematics outside of the classroom in the natural world in ways that were meaningful and relevant to young children.

\section{Previous Literature}

Traditional views of learning mathematics as isolated and grounded in repetition and print-based worksheets and textbooks have been disrupted by recent sociocultural approaches that acknowledge the importance of situating mathematics in culturally relevant and real-world contexts. Mathematic tasks and activities featuring socially situated interactions of students using constructivist approaches such as investigation, observation, designing and exploring positions children as active learners and builds agency for learners to see themselves as emerging mathematicians (Katz, 2010; Katz \& Chard, 2000; McClure et al., 2017). For example, McClure and colleagues (2017) assert, "Very young children who are engaged in planning and planting a community garden... begin to think of themselves as math and science kids" (McClure et al., 2017, p. 36). Unfortunately, the desire to measure the progress and readiness of young learners has become an urgent issue for stakeholders in early childhood settings in the United States and globally (Tan, 2017), creating challenges for prioritizing sociocultural approaches to teaching and learning mathematics, especially when considering educational spaces beyond the traditional classroom.

Advocating for moving math beyond the classroom in support of meaningful mathematics learning can be challenging for educators whose own experiences and approaches may be predominantly traditionally based. Current examples of implementation of mathematics outside the classroom are important because they model the kinds of authentic engagement attainable when traditional models of teaching are infused with opportunities for active learning in real-world context such as outdoor classrooms and gardens.

In a recent ethnographic study, Brown et al. (2021) investigated the perspectives of various stakeholders in Texas and West Virginia regarding public school readiness in kindergarten. The stakeholders included kindergarten students, their families, teachers, administrators at the local- and state-level, as well as policymakers and lobbyists. The overarching implication from stakeholders was that there is fear that constant focus on future readiness for young learners diminishes acknowledging the unique needs of each child and "may ignore the immediate needs of children" (p. 137). One way to ensure that young learners immediate needs are met is to nurture their learning in environments that facilitate mathematical learning via gardening in STEM curricular after-school settings. For example, a European STEM resource handbook was created in which Lindner (2020) explains that for young learners to participate in STEM, they must be actively involved and include elements that "deal with water, living plants, with wood and the earth" (p. 36), which include local contexts such as gardens. 
Outdoor learning environments like gardens provide a space for young learners to use their skills, connect these skills in academic ways, and coconstruct their learning (Rahm, 2002; Thorp, 2006). Unfortunately, the integration of outdoor education was marginalized in the United States during the mid through late $20^{\text {th }}$ century, and continues to be marginalized, due to a focus on educational priorities that were solely aligned with producing students able to compete in a competitive international workforce via standards-based education (Torquati et al., 2013). The urgency for young learners to have authentic experiences across academic content areas with STEM in outdoor places has been documented in the literature. Recent literature includes: engineering and children's funds of knowledge, (Denton \& Borrego, 2021), growing and caring for cotton seeds (Kyoung et al., 2020), solving gardening problems and providing student led solutions based on an inquiry-based engineering process (Mano et al., 2019), analyzing soil content brought into a classroom setting with pre- and in-service teachers and a classroom of kindergarten students (Counsell et al., 2017), and a multi-sited ethnography which analyzed the ways that learners engaged in understanding informal science learning environments and identity construction in three separate out-of-school learning settings (Rahm, 2010). A preponderance of empirical studies focus solely on educator and student experiences through a science content lens in early childhood studies.

There are a limited number of studies focused on how gardening can be used to engage young learners in mathematics content standards including perspectives of the science and math discussions preschoolers have with their classroom teacher in their outdoor classroom (Vandermaas-Peeler \& McClain, 2015). Available studies on STEM and math integration highlight the use of materials in a classroom setting. For example, Aldemir and Kermani's (2016) analyzed the experiences that four early childhood Head Start classroom teachers and students had with an experimental intervention or control group using interactive STEM materials, some of which materials were focused on mathematics. The researchers found that the two teachers in the experimental group expressed an increased perception of confidence about how to integrate STEM concepts with STEM focused materials. As a teacher educator and researcher, I seek to contribute to the growing body of early childhood mathematics practitioner research with this account of my experiences using a classroom garden for engaging young children with mathematics and ongoing articulation of their mathematical identity.

\section{Positionality}

As I conceptualized the FEAR Factor after school program, I intentionally designed it to be a space focused on STEM inquiry and learning for young children. My positionality as a former mathematics teacher allowed me to implement a vision for the afterschool program that balanced 
mathematic content standards while also scaffolding opportunities for play, discussion, and hands-on learning between children and their families.

Facilitating a student-centered garden classroom required that I assume the role of facilitator and observer. Rather than lectures, demonstrations, and formal assessment, my role became focused on creating opportunities for students to engage with one another while planning, creating, and maintaining a garden space. In this position, I was able to interact with students by asking questions, posing various problems, and listening to their metacognitive processes while encouraging math talk focused on inquiry-based learning. This role afforded me access as a researcher to observe the impact of gardening on young children's mathematical learning and positioned me to understand what kinds of mathematical identities and connections were experienced during gardening.

\section{Context and Rationale}

A lack of engagement with mathematics for young children who have transitioned to elementary school is perhaps not surprising given the focus on preparing young children for assessments and high stakes testing. All too often we see early elementary classrooms that have grown accustomed to approaching mathematics with a lack of rigor and relevance using a model of watch the teacher solve problems like this, students try it, students practice this and memorize that, take a test, and repeat. For teachers, this model of repetition is easy to adopt when bombarded with state standards, high stakes accountability, and other classroom responsibilities. For most young learners, this model is far from engaging and increases the lack of passion for mathematics. Learners of all ages deserve to be excited about mathematics and the passion it can inspire for inquiry. They deserve to be challenged with real-world opportunities to make mathematics memorable and relevant to their everyday lives.

As I began working with a group of children in kindergarten, first grade, and second grade, I knew that time was slipping away to instill a passion for mathematics at an early age. I set out to create a class that not only met the grant requirements and objectives, but also create opportunities to invite mathematics into their lives, not merely to improve their practice and provide a foundation, but to inspire a passion for naturally curious mathematicians.

\section{The FEAR Factor Garden}

From my personal experiences as a former elementary teacher, I knew that young children were naturally inquisitive about nature-watching seeds sprout, and other similar activities surrounding plants and gardening. In the past, I used some of these activities in my classroom to engage young learners in STEM and provide opportunities for them to explore and learn about the 
parts of a flower and their functions, the life cycle of plants, photosynthesis, and other concepts mostly in life science. I had not considered the possibility of using gardening to leverage children's curiosity and interest in mathematics, and I was profoundly aware of the challenges surrounding securing a space on campus to use as a garden. I also knew the need to balance demands of high stakes accountability in core subjects like mathematics and garner the support of administrators who might not be keen on teaching mathematic concepts through gardening.

\section{FEAR Factor Garden Space and Preparation}

As the site coordinator, I was the administrator for the FEAR Factor Program, so garnering administrative support was no longer a challenge. There was a 40ft-by-40ft available spot outside my office that was secured with a fence, no longer making find a space an obstacle. I asked the school district for permission to transform the desolate and unused space into the FEAR Factor Garden. The district agreed and provided support in preparing the space for a garden by tilling, installing landscape edging, and planting a tree (see Figure 1). Prior to the district's support, several students in 6th grade helped measure the space and made a drawing to scale of the space. I prepared an opportunity for students in grades K-6 to participate in brainstorming how to design the initial set up of the garden space using the drawing to scale created by the $6^{\text {th }}$ grade students. As a group, students decided to divide the space into four equal sections. The intent was that students in grades $\mathrm{K}-2^{\text {nd }}$ would have one section, $3^{\text {rd }}-4^{\text {th }}$ another section, $5^{\text {th }}-6^{\text {th }}$ a different section, and the remaining section was communal between all grades. Although we attempted to remain true to this design plan, it became logistically difficult and impossible because some maintenance tasks were easier for older students to complete (i.e., using heavy or sharp tools for maintenance), students became more interested in other sections of the garden (i.e., watermelon harvesting time), and students' families were interested in using this space for family engagement activities.

\section{Mathematics Learning Standards for Early Childhood Learners}

As a $21^{\text {st }}$ CCLC administered by TEA we were expected to follow the Texas Essential Knowledge and Skills (TEKS), which are the adopted content standards for what students in the state of Texas should be able to know and do. However, for the purposes of this article, I use the Common Core State Standards (CCSS) (CCSSO, 2010) to describe how standards for mathematics were used in gardening activities because 41 states in the U.S. and the District of Columbia have adopted the CCSS, and I feel using the CCSS is more accessible to most readers. Although the CCSS are organized by grade-level like other state standards including TEKS, I used them as a roadmap in our garden community to meet learners where they were. Since the program was focused on improving academic learning, some of the learners were not 
performing grade-level standards while others were performing above their grade level. The garden provided a space where differentiation came naturally and learners were able to be challenged, yet not become frustrated.
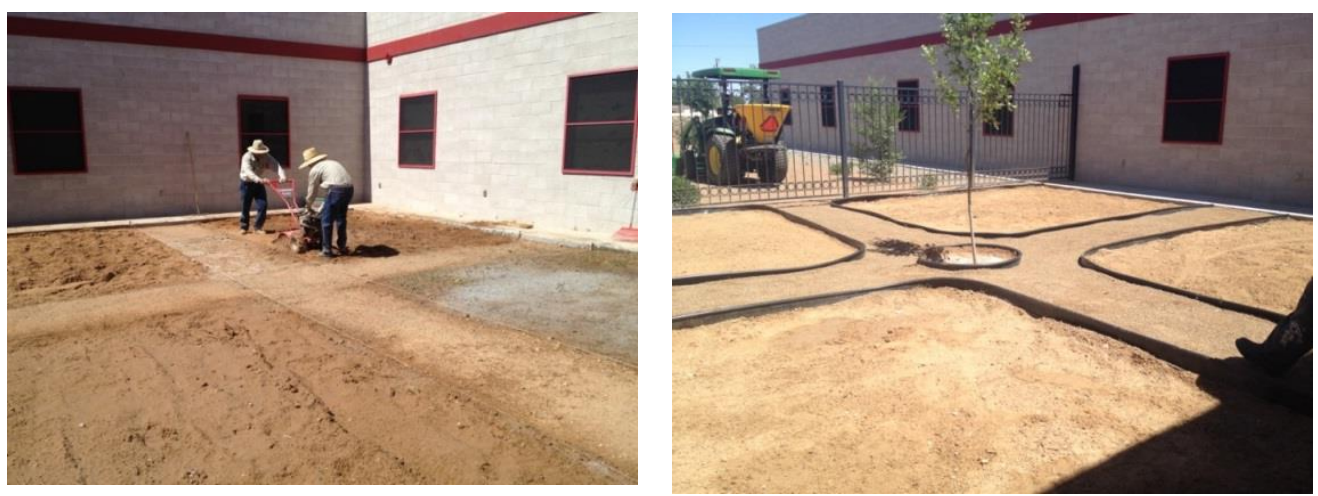

Figure 1. School district workers help prepare The FEAR Factor Program Garden

According to the mathematics CCSS (CCSSO, 2010), children in kindergarten should be able to represent and compare whole numbers with and without sets of objects as well as describe shapes and space. Extending on this knowledge, CCSS expectations for children in first grade are that they be given opportunity to develop their understanding of linear measurement and measure lengths as iterating length units, develop an understanding of strategies for addition and subtraction with 20, develop an understanding of whole number relationships and place value, and reason about attributes of geometric shapes. Building upon this knowledge, CCSS expect that children in second grade will build fluency with addition and subtraction, use standard units of measurement, extend understanding of base-ten notation, and describe and analyze shapes. Standards for Mathematical Practice are also included in the CCSS and include ways children can develop and demonstrate their understanding of and capacity to do mathematics. The eight standards include: 1) Make sense of problems and persevere in solving them; 2) Reason abstractly and quantitatively; 3) Construct viable arguments and critique the reasoning of others; 4) Model with mathematics; 5) Use appropriate tools strategically; 6) Attend to precision; 7) Look for and make use of structure; and 8) Look for and express regularity in repeated reasoning (CCSSO, 2010).

\section{Results: A Young Community of Learners Design and Create the FEAR Factor Garden}

I worked with a young community of learners for approximately 45 minutes three to four days out of the week. Though students learned about science, reading and other content areas during this time, I was intent about focusing on mathematics based on student's academic needs and my experience as a former middle school mathematics teacher. The young community of learners in grades K-2 initially engaged in meaning making in 
the garden through designing and planting. In the following section, I discuss my observations of, and interactions with, children engaged with mathematics, doing mathematics, and using math talk as they designed and planted the FEAR Factor garden.

When initially planting the garden, I provided small groups of children with a predetermined space to work. In this place, they were expected to plant a group of flowers, vegetables, or fruits taking into consideration the space needed between plants, selecting appropriate tools for both measurement and gardening, and using any design elements they wished (i.e., grouping by color or type of plant). I read aloud the suggested planting steps from the card provided including the approximate distance suggested for planting apart, and then I demonstrated how to use non-standard units of measurement (i.e., a hand length) to estimate the distance between plants and facilitated a discussion about other tools that could be used as non-standard and standard lengths or measurement. Children were given autonomy as a group to decide amongst themselves how to accomplish the task of designing the space and planting the set of plants provided to their group.

Most children began the task by counting the number of flowers I gave the group. Some children counted by ones while others used skip counting by two as a strategy. A few children subitized, or recognized the number without counting, which "is a fundamental skill in the development of children's understanding of number" (Baroody, 1987, p. 115). I observed that all children demonstrated early numerical knowledge through one-to-one correspondence and cardinality though all children did not demonstrate their ability to subitize in this activity. However, this activity did not require subitizing because children were able to use their own strategies for determining the total number of plants given to their group.

After determining the total number of plants in the group, children then divided the number of plants equally amongst the members of their group. All groups used the same method of fair sharing to divide the plants amongst themselves by selecting their favorite plant and then letting the next person select until each member had a turn. Then, they repeated the process until all plants were distributed. Out of the different groups, not one opted to use a standard algorithm to divide the flowers amongst themselves. I did not create a scenario where there was a remainder of flowers left over. In hindsight, this was a missed opportunity for students ready to explore and think about how to deal with remainders in this context.

After dividing the flowers amongst themselves, children engaged in a discussion about design and how they imagined their space prior to digging and planting. During this discussion, students negotiated with one another discussing different options for sorting and organizing the plants-based on color, plant type, pattern, etc. They took turns placing the plants in their area representing their individual and collective design ideas. These discussions provided students with opportunities to build capacity in constructing a viable 
argument and critiquing the reasoning of others (Mathematical Practice Standard 3). Once the group agreed upon a design, they dug holes and planted their plants. Figure 2 shows the design outcome of a section where a group of four children in grades 1 and 2 chose to create a pattern (ABB or red-whitewhite) using two different types of flowers. I extended their thinking by asking them to consider what they would have done differently if they had additional colors. They considered different rules for the pattern they could have created in the given scenarios. Although identifying, repeating, and growing patterns are not explicitly mentioned in the mathematics CCSS for children in grades $\mathrm{K}-2$, engaging students in pattern activities provides them with opportunities to generalize patterns in the real-world and recognize structure and mathematics in various scenarios; thus, building capacity for students to look for and make use of structure and express regularity in repeated reasoning (Mathematical Practice Standard 7 and 8).
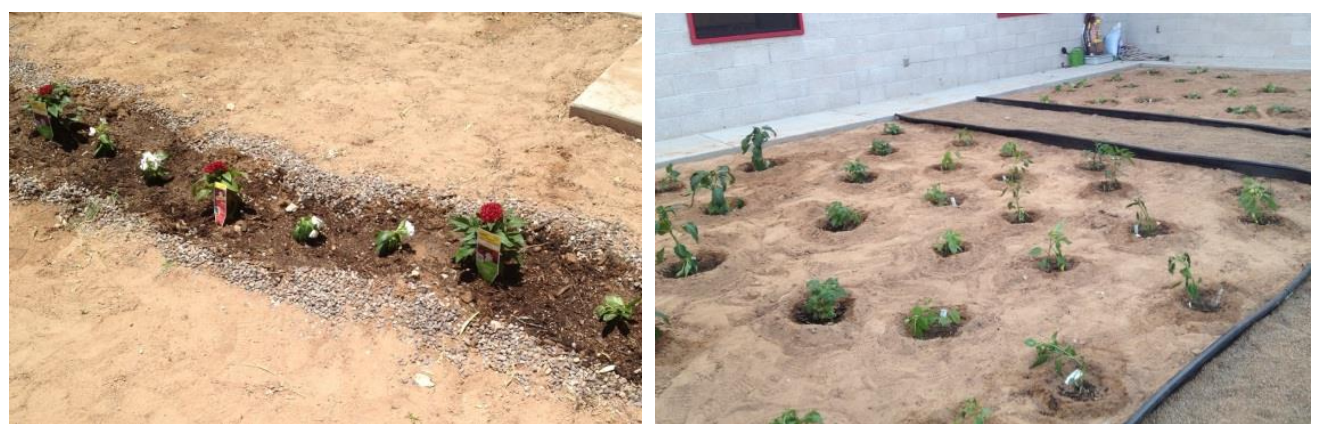

Figure 2. Using a pattern as a design element in the FEAR Factor Garden

Each child was responsible for planting at least one plant in their small group. This provided an opportunity for equal participation and gave each child autonomy in deciding how their plant would fit into the group's design and where they would place their flower. Figure 3 shows a $1^{\text {st }}$ grade community member using her hand as a non-standard unit of measurement to determine the distance needed between her plants. When I asked the group why the distance between each plant was different, one student explained it was because everyone in their group had different sized hands and they were using their own hands to measure the distance. I extended this conversation asking if there was any tool in the garden that they could have used to make the distance equal between their plants. A different student explained how they could have used their shovels because they were the same size. Selecting and using appropriate tools strategically (Mathematical Practice Standard 5) is a mathematical skill that young children develop overtime with practice and reasoning. Math talks such as the one described in this scenario provides students with an opportunity to think about and practice using appropriate tools to accomplish a given task. 


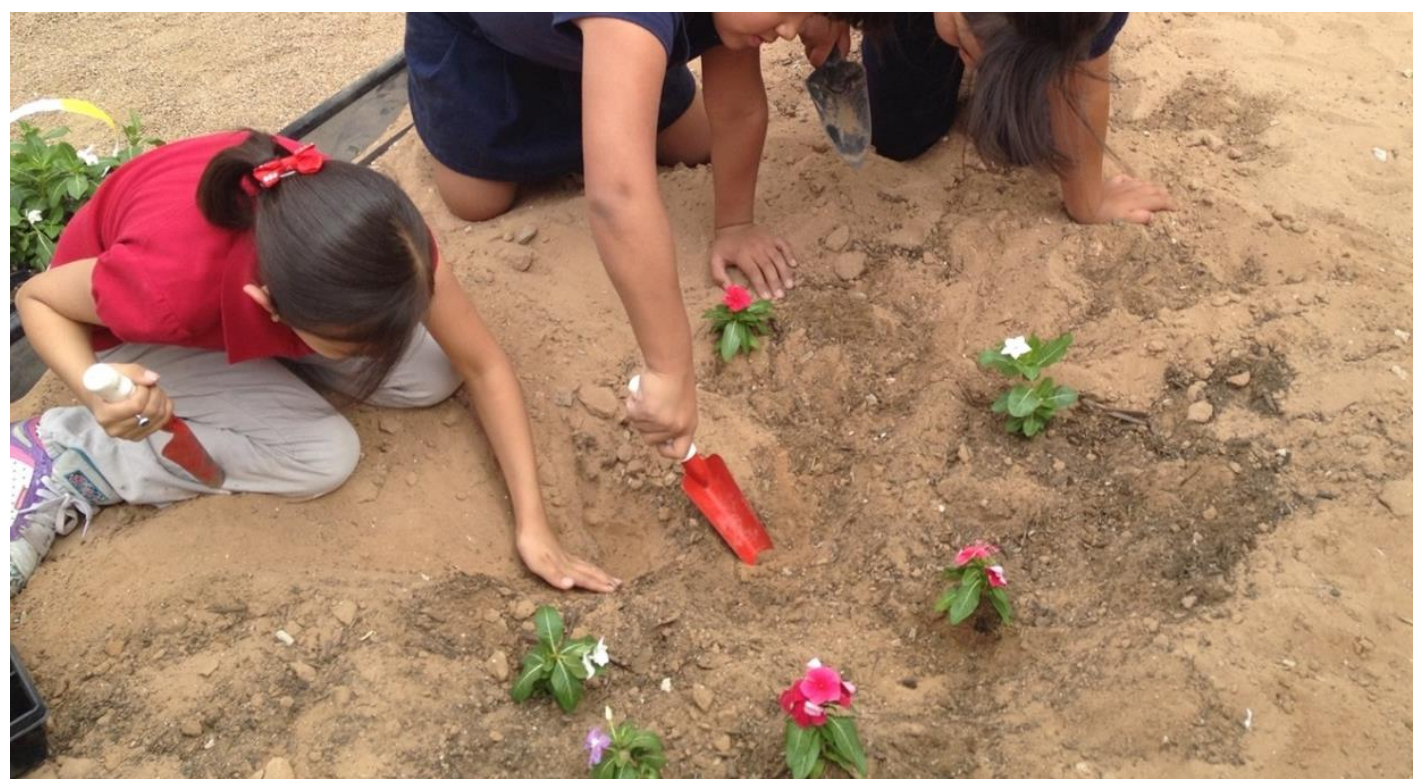

Figure 3. Children using non-standard units of measurement in the FEAR Factor Garden

Finally, a group of children in grade 2 attempted to use an array in their design building upon a different group's design (Figure 4). When prompted about why they agreed to use an array, one student responded that they liked the way it looked. Another student said they thought it would help them count the vegetable plants easier, and a different student explained they had seen arrays used in farms before. The group seemed unsure of their design because they continued their discussion focusing on how they combined tomatoes and jalapeños in the same row and thought this was a mistake. When asked to consider why they grouped the plants the way they did, one student showed us how all the same plant type was planted in the diagonal of the array. I pointed to the largest diagonal and asked the student if he could tell me how many plants were in it. The students counted by ones providing the correct answer but not demonstrating how an array can be used to skip-count or organize quantities.

After design and creation of The FEAR Factor Garden, the young community of practitioners

continued their engagement in meaning making through imagination and multiple interactions as they developed an understanding of maintaining and harvesting The FEAR Factor Garden. Children were provided with opportunities to actively participate in activities such as watering plants, removing weeds, monitoring the health and growth of plants, making predictions about which plants would produce more fruits and vegetables, troubleshooting any issues (i.e., why some plants died), making conjectures about what they would do the same or differently when designing and planting 
their next crop, and collecting data after the harvest. Further investigation and analysis of these activities is warranted but beyond the scope of this article.

\section{Discussion}

As I facilitated the classroom garden space, I intentionally designed it to be a natural space where students interacted with one another as a community of practitioners. I created meaningful opportunities for students to engage with activities focused on mathematics exploration, inquiry, and discussion that supported and supplemented the children's learning during school time in their classrooms. The results suggest children were afforded a diversity of opportunities to engage with mathematics experiences over the course of one semester working in The FEAR Factor Garden. Through regular participation in a variety of gardening activities focused on designing and planting, young children engaged in mathematic-rich dialogue utilizing complex and abstract mathematic process skills such as making sense of problems and persevering in solving them, constructing viable arguments, critiquing the reasoning of others, strategically using appropriate tools, as well as looking for structure regularity in repeated reasoning.

Additionally, young children were able to engage with mathematic concepts such as: linear measurement using non-standard and standard units of measurement; counting by ones, skip-counting, and subitizing; fair sharing; organizing and categorizing objects; describing spaces, and developing spatial reasoning. Previous research suggests that using real-world contexts to engage students in meaningful, goal-oriented activities develops the mathematical thinking and reasoning skills of young learners (Anderson \& Gold, 2006; Gauvain, 1993; Lindner et al., 2011; Saxe \& Posner, 1983), and the results of this study indicate that gardening activities fostered opportunities for children to practice these skills through a flexible programming structure.

Furthermore, upon reflection as a teacher and administrator, I was able to identify the pedagogical possibilities of developing STEM themed projectbased learning for early childhood students eager to learn about nature. Designing, creating, and maintaining The FEAR Factor Garden provided an opportunity to see the pedagogical connections between mathematics and science. For example, algebraic reasoning was associated with finding simple and growing patterns of flower colors, measurement was used to determine height of plants/flowers, and measurement of time was used when considering the growth/maturity of flowers and plants. Additionally, basic geometric shapes were identified in the plants and flowers, and probability and data analysis were connected to predicting and determining the number of red or white flowers. The connections found in nature provided relevant opportunities to explore the relationship between math and science. Additionally, intentional opportunities were designed for young children to use scientific investigations and processes in the garden to observe, 
experiment, predict, and validate scientific reasoning about the structures and processes of living things and their interdependence. Moving forward, I would use gardens to extend children's engagement with other content areas including science, literacy, and social studies.

As I reflect upon using The FEAR Factor Garden as an outdoor classroom to engage students in math, I am impressed by the children's capacity to use academic vocabulary as they designed and created a garden space. Likewise, I was impressed by the children's knack to collaborate with one another to solve problems and use prior knowledge to create viable arguments and critique one another's reasoning. As a current university teacher educator, this first-hand experience and understanding equips me with innovative ways to design interactions which prepare preservice teachers to effectively use outdoor spaces as an extension of their classroom. I believe these embedded preservice experiences would intentionally model how to engage young learners in mathematical thinking and reasoning as well to integrate mathematics with science and other content areas.

One limitation to this study was the research design lacked the rigor of some empirical studies. However, all the interactions and discourse observed in this study occurred naturally in the context of working in the FEAR Factor Garden, and the results have implications for teaching mathematics in early childhood settings. For example, the findings point to the potential of using outdoor gardens to foster integrated approaches to learning. Creating opportunities for young learners to design and plan a garden offers diverse learning opportunities in mathematics. Further research on the mathematic learning opportunities afforded to young children when maintaining and harvesting a garden is warranted. Although the secured funding, allotted space, and administrative support attributed to the success and implementation of the FEAR Factor Garden, this could be a possible limitation for researchers and early childhood educators with limited resources and support who wish to create an outdoor garden or replicate this study.

\section{Conclusion}

One of the positive aspects I found of structuring a STEM based afterschool program was that the schedule was not as constricted as it is for homeroom schoolteachers during a typical school day. This is one of the noted benefits mentioned by Calabrese Barton (2003) since structuring after-school programs around STEM allows for flexible programming. Therefore, learners can co-construct their learning and engage differently with content than they typically might during their regular school day. Furthermore, the absence of utilizing formal assessments allowed for a more relaxed learning environment focusing on student inquiry. However, utilizing formal assessments would provide evidence for those skeptical about the importance of utilizing outdoor garden spaces to make math relevant to young learners. 
In a recent report on the state of STEM in early childhood education, McClure et al. (2017) found that "it is rare that STEM researchers develop a research program to inform or influence policy and practice in the pre-K through third grade years" (p. 31). A proposed solution by this study was for researchers and teachers to work collaboratively to ensure that results from research are applicable to teachers in the field. Kane (2016) noted that educational researchers must provide insight to the practices that are realistic and scalable in real-world classrooms. In this way, researchers can provide practitioners and policymakers with the evidence they need to implement more effective policies that directly translate to practices in early childhood classrooms. Education reform which supports early childhood learning and STEM should be informed by an iterative process that considers the expertise of both scholars and educators (Penuel \& Farrell, 2016). This manuscript provides insight to the way I adjusted my pedagogical design to support the developmental learning that early learners experienced via mathematics, situated in an outdoor garden.

\section{References}

Abodeeb-Gentile, T., \& Zawilinski, L. (2013). Reader identity and the Common Core: Agency and identity in leveled reading. The Language and Literacy Spectrum, 23, 34-45.

Aldemir, J. \& Kermani, H. (2016). Integrated STEM curriculum: improving educational outcomes for Head Start children. Early Child Development and Care, 187, 1-13.

Anderson, D.D. \& Gold, E. (2006). Home to school: Numeracy practices and mathematical identities. Mathematical Thinking and Learning, 8, 261286.

Baroody, A. J. (1987). Children's mathematical thinking: A developmental framework for preschool, primary, and special education teachers. New York: Teachers College Press.

Blankenship, M.U., \& Margarella, E.E. (2014). Technology and secondary writing: A review of the literature. Contemporary Educational Technology, 5(2), 146-160.

Brown, C. P., Barry, D. P. \& Ku, D. H. (2021). How education stakeholders made sense of school readiness in and beyond kindergarten. Journal of Research in Childhood Education, 35(1), 122-142.

Calabrese Barton, A. (2003). Teaching science for social justice. New York, NY: Teachers College Press.

Clements, D. H. (2001). Mathematics in the preschool. Teaching Children Mathematics, 7, 270-275.

Council of Chief State School Officers. (2010). Common core state standards. Washington, DC.

Counsell, S., Jacobs, K., \& Gatewood, S. (2017). What's in Our Soil? Science and Children, 55(1), 58-64. 
Denton, M., \& Borrego, M. (2021). Funds of knowledge in STEM education: A scoping review. Studies in Engineering Education, 1(2), 71-92.

Gauvain, M. (1983). The development of spatial thinking in everyday activity. Developmental Review, 13, 92-121.

Kane, T. (2016). Connecting to practice: How we can put educational research to work. Retrieved from http://educationnext.org/connectingto-practice-put-education-research-to-work/

Katz, L. G. (2010). STEM in early years. Paper presented at the SEED (STEM in Early Education and Development) Conference, University of Northern Iowa, Cedar Falls, Iowa, USA. Retrieved from http://ecrp.uiuc.edu/beyond/seed/katz.htm

Katz, L. G., \& Chard, . C. (2000). Engaging children's minds: The project approach (2nd ed.). Stamford, CT: Ablex.

Kyoung J. K., Jung, E., Han, M.K. \& Sohn, J. H. (2020) The power of gardenbased curriculum to promote scientific and nature-friendly attitudes in children through a cotton project. Journal of Research in Childhood Education, 34(4), 538-550.

Lidner, M. (2020). STEM activities should be embedded in a local context, In Ş.Ünlü Çetin, K. Bilican and M. Üçgül (Eds.), Key points for STEM in Early Childhood Education and involving parents: A guidebook for early childhood educators (pp.10-13), An intellectual output of the 2018-1-TR01-KA203-059568 PARENSTEM: STEM Education for Preschoolers and Their Families Project, Krkkale Univers ty.

Lindner, S.M., Powers-Costello, \& Stegelin, D. A. (2011). Mathematics in early childhood: Research-based rational and practical strategies. Early Childhood Education Journal, 39, 29-37.

Lipman, M. (2010). Thinking in education (2nd ed.). New York, NY: Cambridge University Press.

Mano, H., Molina, K., Lange, A., \& Nayfeld, I. (2019). Engineering encounters: Planting the seeds of engineering preschoolers think about, talk about, and solve a real problem in the garden. Science and Children, 57(2), 80-84.

McClure, E. R., Guernsey, L., Clements, D. H., Bales, S. N., Nichols, J., Kendall-Taylor, N., \& Levine, M. H. (2017). STEM Starts Early. Education Digest, 86(4), 43-51.

Penuel, W. R., \& Farrell, C. C. (2017). Research-practice partnerships and ESSA: A learning agenda for the coming decade. In E. Q. (Ed.), Teaching in context: The social side of education reform (pp. 181200). Harvard Education Press.

Perlmutter, J., Bloom, L., Rose, T. \& Rogers, A. (1997). Who uses math? Primary children's perceptions of the uses of mathematics. Journal of Research in Childhood Education, 12(1), 58-70.

Rahm, J. (2002), Emergent learning opportunities in an inner-city youth gardening program. Journal of Research in Science Teaching, 39, 164184. 
Rahm, J. (2010). Science in the making at the margin: A multisited ethnography of learning and becoming in an afterschool program, a garden and a math and science upward bound program. Rotterdam, The Netherlands: Sense Publishers.

Saxe, G.B. \& Posner, J. (1983). The development of numerical cognition: Cross-cultural perspectives. In H.P. Ginsburg (Ed.), The development of mathematical thinking (pp. 291-317). London: Academic Press.

Tan, C. T. (2017). Enhancing the quality of kindergarten education in Singapore: Policies and strategies in the 21st century. International Journal of Child Care and Education Policy, 11, 1- 22.

Thorp, L. (2006). The pull of the Earth: Participatory ethnography in the school garden. Lanham, MD: AltaMira Press.

Torquati, J., Cutler, K. Gilkerson, D. \& Sarver, S. (2013). Early childhood educators' perceptions of nature, science, and environmental education. Early Education and Development, 24(5),721-743.

Vandermaas-Peeler, M., \& McClain, C.M. (2015). The green bean has to be longer than your thumb: An observational study of preschoolers' math and science experiences in a garden. International Journal of Early Childhood Environmental Education, 3(1), 8-27.

\section{Author's Bio:}

Dr. Leanna Lucero (she/her/hers) holds a Ph.D. in Teaching, Learning, \& Culture with an emphasis on Mathematics, Science, and Technology Education from the University of Texas at El Paso. She is an assistant professor in the School of Teacher Preparation, Administration, and Leadership at New Mexico State University, where she teaches preservice teachers. Her scholarship focuses on social justice complexities in teacher education with an emphasis on STEM disciplines and queer studies in education. She is dedicated to supporting and giving voice to populations that may not know how to access and navigate their rights in today's classroom, school systems, and world.

Email: leannal@nmsu.edu

ORCiD: 0000-0002-1055-0191 